\title{
Coping with antibiotic resistance: contributions from genomics
}

\author{
Gian Maria Rossolini* and Maria Cristina Thaller²
}

\begin{abstract}
Antibiotic resistance is a public health issue of global dimensions with a significant impact on morbidity, mortality and healthcare-associated costs. The problem has recently been worsened by the steady increase in multiresistant strains and by the restriction of antibiotic discovery and development programs. Recent advances in the field of bacterial genomics will further current knowledge on antibiotic resistance and help to tackle the problem. Bacterial genomics and transcriptomics can inform our understanding of resistance mechanisms, and comparative genomic analysis can provide relevant information on the evolution of resistant strains and on resistance genes and cognate genetic elements. Moreover, bacterial genomics, including functional and structural genomics, is also proving to be instrumental in the identification of new targets, which is a crucial step in new antibiotic discovery programs.
\end{abstract}

\begin{abstract}
Antibiotic resistance as a global public health problem The advent of antibiotics for treating bacterial infections is considered one of the major advances in modern medicine. However, compared with other drugs, the lifetime of antibiotics for clinical use has been substantially limited by the phenomenon of antibiotic resistance. Failures of antimicrobial chemotherapy due to resistance were observed soon after the introduction of penicillin in clinical practice and, thereafter, the emergence of resistance has always followed the release of new antibiotics, posing a major clinical challenge and at the same time acting as a major driver for drug discovery and development in the field of antimicrobial agents.
\end{abstract}

*Correspondence: rossolini@unisi.it

'Department of Molecular Biology, Section of Microbiology, University of Siena, and Clinical Microbiology Unit, Siena University Hospital, Policlinico Santa Maria alle Scotte, Viale Bracci, 53100 Siena, Italy

Full list of author information is available at the end of the article
Antibiotic resistance is now recognized as a major public health problem because of its magnitude and global scale. In fact, resistance does not affect only industrialized countries (where this is expected given the unlimited access to the antibiotic market) but also lowincome settings, where resistance rates have been found to be even higher because of less well regulated antimicrobial policies and worse hygiene conditions and infection-control practices [1]. It is also well documented that resistance has a significant impact in terms of morbidity, mortality and healthcare-associated costs [2]. For instance, infections caused by methicillin-resistant Staphylococcus aureus (MRSA, one of the most widespread and challenging resistant superbugs) were shown to be associated with an increased risk of mortality (almost twofold for bacteremias; more than threefold for surgicalsite infections) in comparison with infections of the same type caused by methicillin-susceptible $S$. aureus (MSSA). There is also a positive correlation with the length of stay in hospital and the healthcare-associated costs of handling MRSA infections compared with MSSA infections [2].

Although antibiotic resistance continues to evolve at a steady pace and the spreading of resistant strains has been facilitated by increasing international travel and migration, most pharmaceutical companies have also recently chosen to restrict programs aimed at the discovery and development of new antibiotics. This has plunged the phenomenon of antibiotic resistance into a major crisis, with the increasing emergence of strains that are resistant to most or all antibiotics currently available for clinical use [3], which threatens to turn the clock back to the pre-antibiotic era.

Here, we briefly review and discuss how the recent advancement of bacterial genomic sciences can contribute to further current knowledge on resistance and to find new solutions to address this important problem.

\section{The genetics of antibiotic resistance}

Acquired antibiotic resistance can be due to a plethora of mechanisms (Table 1). These include, first, drug inactivation, for example by $\beta$-lactamases and aminoglycosidemodifying enzymes, which confer resistance to $\beta$-lactams and aminoglycosides, respectively; second, drug target 
Table 1. Examples of clinically relevant resistance mechanisms in major bacterial pathogens

\begin{tabular}{|c|c|c|c|}
\hline Resistance mechanism & Molecular basis & Antibiotics affected & Relevant clinical pathogens \\
\hline \multirow[t]{2}{*}{ Drug inactivation } & $\beta$-Lactamases & $\begin{array}{l}\beta \text {-Lactams (variable spectrum, } \\
\text { depending on the enzyme type) }\end{array}$ & $\begin{array}{l}\text { Many Gram-positive and Gram-negative } \\
\text { pathogens }\end{array}$ \\
\hline & $\begin{array}{l}\text { Aminoglycoside-modifying } \\
\text { enzymes }\end{array}$ & $\begin{array}{l}\text { Aminoglycosides (variable } \\
\text { spectrum, depending on the } \\
\text { enzyme type) }\end{array}$ & $\begin{array}{l}\text { Many Gram-positive and Gram-negative } \\
\text { pathogens }\end{array}$ \\
\hline \multirow[t]{3}{*}{ Target modification } & Mutated DNA topoisomerases & Quinolones and fluoroquinolones & $\begin{array}{l}\text { Many Gram-positive and Gram-negative } \\
\text { pathogens }\end{array}$ \\
\hline & Mutated RNA polymerase & Rifampin & $\begin{array}{l}\text { Staphylococcus aureus, } \\
\text { Mycobacterium tuberculosis }\end{array}$ \\
\hline & $\begin{array}{l}\text { Altered peptidoglycan } \\
\text { (presence of D-Ala-D-Lac } \\
\text { depsipeptide) }\end{array}$ & Glycopeptides & Enterococci \\
\hline \multirow[t]{4}{*}{ Target protection } & $\begin{array}{l}235 \text { ribosomal RNA methylation } \\
\text { by Erm methylases }\end{array}$ & Macrolides & Streptococci, Staphylococci, anaerobes \\
\hline & $\begin{array}{l}16 \mathrm{~S} \text { ribosomal RNA methylation } \\
\text { by Arm/Rmt-like methylases }\end{array}$ & Aminoglycosides & Enterobacteriaceae \\
\hline & Ribosomal protection by Tet proteins & Tetracyclines & Many Gram-positive pathogens \\
\hline & $\begin{array}{l}\text { Topoisomerase protection by } \\
\text { Qnr proteins }\end{array}$ & Quinolones and fluoroquinolones & Enterobacteriaceae \\
\hline Bypass of target function & $\begin{array}{l}\text { Production of PBP2a, which takes over } \\
\text { the functions of other PBPs }\end{array}$ & Most $\beta$-lactams & $\begin{array}{l}\text { Methicillin-resistant Staphylococcus aureus } \\
\text { (MRSA) }\end{array}$ \\
\hline Impermeability & Loss of OprD porin & Carbapenems & Pseudomonas aeruginosa \\
\hline \multirow[t]{3}{*}{ Drug efflux } & Tet MFS-type pumps & Tetracyclines & Enterobacteriaceae, Staphylococci \\
\hline & $\begin{array}{l}\text { Upregulation of MexAB RND-type } \\
\text { pump }\end{array}$ & $\begin{array}{l}\text { Fluoroquinolones and most } \\
\text { anti-pseudomonal } \beta \text {-lactams }\end{array}$ & Pseudomonas aeruginosa \\
\hline & Upregulation of MexXY RND type pump & $\begin{array}{l}\text { Fluoroquinolones, aminoglycosides, } \\
\text { cefepime and meropenem }\end{array}$ & Pseudomonas aeruginosa \\
\hline
\end{tabular}

PBP: penicillin-binding-protein.

modification by mutation, such as DNA topoisomerase or RNA polymerase modifications, conferring resistance to quinolones and rifampicin, respectively; third, drug target protection, for example ribosomal methylation conferring resistance to aminoglycosides or macrolides, or topoisomerase protection by Qnr proteins conferring resistance to quinolones; fourth, drug target bypass, for example peptidoglycan synthesis by a novel penicillinbinding-protein, PBP2a, conferring resistance to $\beta$-lactams; fifth, impermeability, for example by loss of outer membrane porin channels, conferring resistance to carbapenems; and finally drug efflux, for example by Tet major facilitator superfamily (MFS)-type pumps, conferring resistance to tetracyclines, or by tripartite resistancenodulation-cell division superfamily (RND)-type pumps, conferring a multidrug resistance phenotype. This diversity of resistance mechanisms reflects the broad repertoire of available agents, the multiplicity of their mechanisms of action, the biological diversity of bacteria, and the plasticity of their genomes. From a genetic standpoint, resistance mechanisms can arise either by mutation or by the acquisition and expression of heterologous genes encoding the resistance determinant through horizontal gene transfer mechanisms such as conjugation, transformation or phage transduction.

Once acquired, the resistance determinants confer a selective advantage to the host when it is exposed to antibiotics, which can result in an expansion of the resistant clone relative to susceptible ones; this expansion can assume epidemic or even pandemic dimensions. Typical examples of resistant clones of Gram-positive pathogens that underwent an international dissemination, with remarkable clinical and epidemiological impact, include the MRSA strains belonging to clonal complexes (CCs) 5 and 8 [4], the glycopeptide-resistant Enterococcus faecium strains of CC17 [5] and the several penicillinnonsusceptible pneumococcal clones spreading worldwide [6]. Similar examples of resistant clones of Gram-negative pathogens with high spreading potential include the Escherichia coli clone O25:H4-ST-131, which produces the CTX-M-15 extended-spectrum $\beta$-lactamase (ESBL) [7], the Klebsiella pneumoniae clone (KPC) ST-258, which produces acquired KPC-type carbapenemases [8], and the Acinetobacter baumannii derivatives of major European clone II, which produces oxacillin (OXA)-type carbapenemases [9]. 
Mobile genetic units, such as conjugative plasmids or transposons and lysogenic bacteriophages, can also be very successful in transferring across different strains, leading to a multi-clonal emergence of resistant strains. A typical example is represented by several conjugative plasmids encoding CTX-M-type ESBLs that were responsible for rapid and efficient dissemination of these resistance determinants, conferring resistance to the expandedspectrum cephalosporins, among E. coli [10]. Other examples of mobile genetic elements that contributed significantly to horizontal dissemination of resistance genes are the large conjugative transposons and phage-like elements carrying macrolide resistance determinants of the erm and mef type, responsible for the dissemination of these resistance determinants among different clones of pneumococci and group A streptococci [11].

\section{The role of genomics in surveillance and control of resistance}

Tracing the epidemiology of resistant strains and resistance genes is of paramount importance for surveillance and control of antibiotic resistance, which can no longer rely on the simple phenotypic characterization of bacterial isolates. Molecular epidemiology is the discipline that studies the epidemiology of resistant strains and resistance genes by characterizing them at the molecular level, and it has provided major breakthroughs in the understanding of this phenomenon, with practical implications for resistance control strategies. The information provided by molecular analysis has a variable degree of resolution depending on the analytical tools, with genetic ones being the most versatile and of highest resolution. From this perspective, full genomic analysis of major resistant clones can be very informative for understanding their lifestyle and evolution and would be the golden standard for their comparison, as it was clearly shown with MRSA [12].

Genomic knowledge can also be instrumental to the development of sets of molecular probes for easy and specific identification of resistant clones of high spreading propensity and clinical impact, such as those described above, which is crucial in infection control practices. These probes can be used by reference laboratories or even by the largest diagnostic laboratories, in multiplexed amplification or DNA microarray technologies, for identification of such 'high risk' resistant clones involved in hospital or community outbreaks.

The importance of identifying high risk resistant clones and understanding their evolution explains the considerable effort that has recently been undertaken to sequence the genomes of multiresistant strains of bacterial pathogens [13], such as MRSA (eight projects), Acinetobacter baumannii (five projects), Mycobacterium tuberculosis (three projects) and Pseudomonas aeruginosa (two projects), and also to sequence plasmids involved in the dissemination of important resistance determinants, such as ESBLs, AmpC-type $\beta$-lactamases or (quinolone resistance) Qnr proteins [14].

\section{Genomics can inform our understanding of resistance mechanisms}

Understanding resistance mechanisms to novel drugs is crucial in the process of discovery and development of antimicrobial drugs. Knowledge on newly emerging resistance mechanisms to antibiotics already available for clinical use is also of paramount importance for the prediction of resistance evolution, antibiotic policies and resistance surveillance and control strategies. Genomescale investigations may provide relevant insights into unknown mechanisms of antibiotic resistance.

For instance, a comparative genomic analysis between $S$. aureus strains showing heterogeneous or homogeneous intermediate resistance to vancomycin (hVISA or VISA strains) and the susceptible parent strain has recently revealed the role of mutations of the genes encoding the vraSR and graSR two-component regulatory system in conferring this resistance phenotype, which is associated with clinical failures of glycopeptides [15]. A similar comparative genomic approach, carried out using arraybased methodology, provided insights into mutational mechanisms that, in $S$. aureus, could be responsible for the emergence of reduced susceptibility to daptomycin, a new anti-Gram-positive antibiotic recently released for the treatment of staphylococcal infections [16]. Another genome-scale investigation that advanced our knowledge of resistance mechanisms was that by Breidenstein et al. [17], who, using a comprehensive $P$. aeruginosa mutant library, identified a number of new genes that, when inactivated, are associated with decreased susceptibility to fluoroquinolones in this species. These genes include PA2047 and PA3574, which encode transcriptional regulators, the nuo genes, which encode NADH dehydrogenase I subunits, and several other genes encoding hypothetical proteins.

Transcriptomics at a genome-wide scale has also been used successfully to investigate resistance mechanisms. For example, transcription profiling following ciprofloxacin exposure has revealed an important role of the $m f d$ gene, which encodes a transcription-repair coupling factor involved in strand-specific DNA repair, in the development of fluoroquinolone resistance in Campylobacter jejuni [18]. Transcriptome analysis of S. aureus treated with sublethal concentrations of cationic antimicrobial peptides has revealed a role for several genes, including the vraSR cell wall regulon, in the bacterial response to these agents, as well as a role of the VraDE putative ATP-binding cassette $(\mathrm{ABC})$ transporter in conferring resistance to bacitracin [19]. 


\section{Genomic knowledge and antibacterial drug discovery}

Knowledge on bacterial genomes has progressed at a fast pace during recent years, with almost 1,500 completed bacterial genomes and more than 600 additional genome projects in progress at the beginning of 2010 [13]. Indeed, since its very beginning, the advent of bacterial genomics was not only regarded as a fascinating scientific tool, but also raised great hopes for renewing the golden era of antimicrobial discovery at a time when this is sorely needed because of the growing impact of bacterial resistance. The rationale behind this expectation was that comparative genomic analysis could reveal valuable information on bacterial genes that presumably encode proteins that are essential to survival or fitness of bacterial pathogens and do not have close eukaryotic counterparts; these proteins could then be potential targets for new antimicrobial agents.

This approach has been extensively pursued and has returned some potential targets for new antimicrobial agents that fulfilled the above criteria, including enzymes involved in biosynthetic pathways (for example coenzyme A, chorismate, lipid A and fatty acids), protein synthesis (such as aminoacyl tRNA synthetases and peptide deformylase), protein secretion (such as signal peptidase 1) and DNA replication (such as FtsZ/FtsA) [20,21]. Some two-component signal transduction systems have also been considered [20].

However, it was soon evident that, although identification of potential targets is important, a comprehensive understanding of bacterial biochemistry, physiology and pathogenicity are essential for exploiting this information for antimicrobial drug discovery. After the identification of the potential targets, there are several bottlenecks to be overcome in the process of developing new drugs; in particular, the need to set up high-throughput screening of banks of small molecules to obtain potential hits, which has prompted great efforts in the fields of functional and structural genomics [22]. Moreover, many screenings have turned out to be unproductive, or it was discovered that effective drugs could not be developed from the potential inhibitors [20].

This accounts for the overall dearth of new drugs discovered using genomic approaches that have made it into advanced clinical phases of the antibiotic pipeline after almost 15 years of efforts in this area. However, the natural products platensimycin and platenmycin, produced by Streptomyces platensis, have been discovered to be inhibitors of FabF and/or FabH (enzymes involved in bacterial type II fatty-acid biosynthesis) [23] and are now awaiting further preclinical studies, and some peptide deformylase inhibitors have already entered clinical trials $[20,21]$. Therefore, the potential of microbial genomics for discovery of new drugs should not be underestimated. Indeed, a novel screening technique, combining chemical genomics with a yeast-based assay, has enabled the discovery of both a $P$. aeruginosa virulence-associated target (ExoS) and its inhibitor [24].

Finally, cloning and sequencing metagenomes from various ecological niches in which antibiotic-producing bacteria are expected to be present could reveal new antimicrobial synthetic gene clusters from unknown or uncultured bacteria. This strategy has already yielded some results such as the gene clusters for synthesis of turbomycins A and B, new glycopeptides and other compounds with antimicrobial activity cloned from environmental DNA (eDNA) libraries [25].

\section{Concluding remarks}

Antibiotic resistance is one of the greatest clinical challenges in the treatment of infectious diseases, given that it is a complex phenomenon whose emergence and evolution is still only partially understood. Bacterial genomics provides an invaluable contribution to furthering current knowledge on antibiotic resistance mechanisms and evolution, and on molecular epidemiology of resistance, which is instrumental to infection control practices. Moreover, information from functional and structural genomics has a key role in the identification of novel antimicrobial targets. The number of new agents discovered following this approach that are found in the advanced stages of the antibiotic pipeline is still very limited; however, the exploitation of bacterial genomics has been a major breakthrough for discovery and development of new antibiotics active against multiresistant pathogens.

\section{Abbreviations \\ CC, clonal complex; ESBL, extended-spectrum $\beta$-lactamase; MRSA, methicillin- resistant $S$. aureus; MSSA, methicillin-susceptible $S$. aureus.}

\section{Competing interests}

The authors declare that they have no competing interests.

\section{Authors' contributions}

Both authors contributed to reviewing the relevant literature. MCT analyzed microbial genome databases. GMR wrote the article.

\section{Author details}

'Department of Molecular Biology, Section of Microbiology, University of Siena, and Clinical Microbiology Unit, Siena University Hospital, Policlinico Santa Maria alle Scotte, Viale Bracci, 53100 Siena, Italy

${ }^{2}$ Department of Biology, University of Rome 'Tor Vergata', Viale della Ricerca Scientifica s.n.c. 00133 Rome, Italy

\section{Published: 25 February 2010}

\section{References}

1. Okeke IN, Laxminarayan R, Bhutta ZA, Duse AG, Jenkins P, O'Brien TF, PablosMendez A, Klugman KP: Antimicrobial resistance in developing countries. Part I: recent trends and current status. Lancet Infect Dis 2005, 1:481-493.

2. Maragakis $L L$, Perencevich EN, Cosgrove SE: Clinical and economic burden of antimicrobial resistance. Expert Rev Anti Infect Ther 2008, 6:751-763.

3. Boucher HW, Talbot GH, Bradley JS, Edwards JE, Gilbert D, Rice LB, Scheld M, Spellberg B, Bartlett J: Bad bugs, no drugs: no ESKAPE! An update from the 
Infectious Diseases Society of America. Clin Infect Dis 2009, 48:1-12.

4. Deurenberg RH, Vink C, Kalenic S, Friedrich AW, Bruggeman CA, Stobberingh EE: The molecular evolution of methicillin-resistant Staphylococcus aureus. Clin Microbiol Infect 2007, 13:222-235.

5. Willems RJ, Top J, Santen Mv, Robinson DA, Coque TM, Baquero F, Grundmann H, Bonten MJ: Global spread of vancomycin-resistant Enterococcus faecium from distinct nosocomial genetic complex. Emerg Infect Dis 2005, 11:821-828

6. Woodford N, Livermore DM: Infections caused by Gram-positive bacteria: a review of the global challenge. J Infect 2009, 59:S4-S16.

7. Nicolas-Chanoine M-H, Blanco J, Leflon-Guibout V, Demarty R, Alonso MP, Caniça MM, Park YJ, Lavigne JP, Pitout J, Johnson JR: Intercontinental emergence of Escherichia coli clone O25:H4-ST131 producing CTX-M-15. $J$ Antimicrob Chemother 2008, 61:273-281.

8. Nordmann P, Cuzon G, Naas T: The real threat of Klebsiella pneumoniae carbapenemase-producing bacteria. Lancet Infect Dis 2009, 9:228-236.

9. Higgins PG, Dammhayn C, Hackel M, Seifert H: Global spread of carbapenem-resistant Acinetobacter baumannii. J Antimicrob Chemother 2010, 65:233-238.

10. Valverde A, Cantón R, Garcillán-Barcia MP, Novais A, Galán JC, Alvarado A, de la Cruz F, Baquero F, Coque T: Spread of bla(CTX-M-14) is driven mainly by IncK plasmids disseminated among Escherichia coli phylogroups A, B1, and D in Spain. Antimicrob Agents Chemother 2009, 53:5204-5212.

11. Varaldo P, Montanari MP, Giovanetti E: Genetic elements responsible for erythromycin resistance in streptococci. Antimicrob Agents Chemother 2009, 53:343-353.

12. Harris SR, Feil EJ, Holden MTG, Quail MA, Nickerson EK, Chantratita N, Gardete S, Tavares A, Day N, Lindsay JA, Edgeworth JD, de Lencastre H, Parkhill J, Peacock SJ, Bentley SD: Evolution of MRSA during hospital transmission and intercontinental spread. Science 2010, 327:469-474.

13. NCBI Genome Project [http://www.ncbi.nlm.nih.gov/genomepri]

14. Carattoli A: Resistance plasmid families in Enterobacteriaceae. Antimicrob Agents Chemother 2009, 53:2227-2238

15. Cui L, Neoh HM, Shoji MKH: Contribution of vraSR and graSR point mutations to vancomycin resistance in vancomycin-intermediate Staphylococcus aureus. Antimicrob Agents Chemother 2009, 53:1231-1234.

16. Friedman L, Alder JD, Silverman JA: Genetic changes that correlate with reduced susceptibility to daptomycin in Staphylococcus aureus. Antimicrob Agents Chemother 2006, 50:2137-2145.
17. Breidenstein EBM, Khaira BK, Wiegand I, Overhage J, Hancock RE: Complex ciprofloxacin resistome revealed by screening a Pseudomonas aeruginosa mutant library for altered susceptibility. Antimicrob Agents Chemother 2008 52:4486-4491.

18. Han J, Sahin O, Barton YW, Zhang Q: Key role of Mfd in the development of fluoroquinolone resistance in Campylobacter jejuni. PLoS Pathog 2008, 4:e1000083

19. Pietiäinen M, François P, Hyyryläinen HL, Tangomo M, Sass V, Sahl HG, Schrenzel J, Kontinen VP: Transcriptome analysis of the responses of Staphylococcus aureus to antimicrobial peptides and characterization of the roles of vraDE and vraSR in antimicrobial resistance. BMC Genomics 2009, 10:429.

20. Payne DJ, Gwynn MN, Holmes DJ, Pompliano DL: Drugs for bad bugs: confronting the challenges of antibacterial discovery. Nat Rev Drug Discov 2007, 6:29-40

21. Falconer SB, Brown ED: New screens and targets in antibacterial drug discovery. Curr Opin Microbiol 2009, 12:497-504

22. Monaghan RL, Barrett JF: Antibacterial drug discovery - then, now and the genomics future. Biochem Pharmacol 2006, 71:901-909.

23. Wang J, Kodali S, Lee SH, Galgoci A, Painter R, Dorso K, Racine F, Motyl M, Hernandez L, Tinney E, Colletti SL, Herath K, Cummings R, Salazar O, Gonzalez I, Basilio A, Vicente F, Genilloud O, Pelaez F, Jayasuriya H, Young K, Cully DF, Singh SB: Discovery of platencin, a dual FabF and FabH inhibitor with in vivo antibiotic properties. Proc Natl Acad Sci USA 2007, 104:7612-7616.

24. Arnoldo A, Curak J, Kittanakom S, Chevelev, Lee VT, Sahebol-Amri M, Koscik B, Ljuma L, Roy PJ, Bedalov A Giaever G, Nislow C, Merrill RA, Lory S, Stagljar l: Identification of small molecule inhibitors of Pseudomonas aeruginosa exoenzyme S using a yeast phenotypic screen. PLoS Genet 2008, 4:e1000005.

25. Brady SF, Simmons L, Kim JH, Schmidt EW: Metagenomic approaches to natural products from free-living and symbiotic organisms. Nat Prod Rep 2009, 26:1488-1503.

doi:10.1186/gm136

Cite this article as: Rossolini GM, Thaller MC: Coping with antibiotic resistance: contributions from genomics. Genome Medicine 2010, 2:15. 